\title{
Diabetic nephropathy, autophagy and proximal tubule protein endocytic transport: A potentially harmful relationship
}

\author{
Maximiliano GIRAUD-BILlOUD ${ }^{1,2, *}$; Claudio M. FADER ${ }^{1,3}$; Rocío AGÜERO ${ }^{2}$; Fernando EZQUER ${ }^{4}$ MARCElo EZQUER $^{4}$ \\ ${ }^{1}$ IHEM, Universidad Nacional de Cuyo, CONICET, Mendoza, Argentina \\ ${ }^{2}$ Universidad Nacional de Cuyo, Facultad de Ciencias Médicas, Instituto de Fisiología, Casilla de Correo 33, 5500-Mendoza, Argentina \\ ${ }^{3}$ Universidad Nacional de Cuyo, Facultad de Odontología, Casilla de Correo 33, 5500-Mendoza, Argentina \\ ${ }^{4}$ Centro de Medicina Regenerativa, Facultad de Medicina Clínica Alemana, Universidad del Desarrollo, Avenida Las Condes 12438, Santiago, Chile
}

Key words: Megalin, Cubilin, Type 2 diabetes mellitus

\begin{abstract}
Diabetic nephropathy $(\mathrm{DN})$ is the most frequent cause of chronic renal failure. Until now, the pathophysiological mechanisms that determine its development and progression have not yet been elucidated. In the present study, we evaluate the role of autophagy at early stages of DN, induced in type 2 diabetes mellitus (T2DM) mouse, and its association with proximal tubule membrane endocytic receptors, megalin and cubilin. In T2DM animals we observed a tubule-interstitial injury with significantly increased levels of urinary GGT and ALP, but an absence of tubulointerstitial fibrosis. Kidney proximal tubule cells of T2DM animals showed autophagic vesicles larger than those observed in the control group, and an increase in the number of these vesicles marked with LBPA by immunofluorescence. Furthermore, a significant decrease in the ratio of LC3II/LC3I isoforms and in p62 protein expression in DN affected animals is shown. Finally, we observed a marked increase in urinary albumin and vitamin D binding-protein levels in T2DM animals as well as a significant decrease in expression of megalin in the renal cortex. These results indicate an alteration of the tubular endocytic transporters in DN, which could be related to autophagic dysfunction, which would in turn result in impaired organelle recycling, thus contributing to the progression of this disease.
\end{abstract}

Diabetic nephropathy $(\mathrm{DN})$ is a clinical syndrome characterized by proteinuria and progressive renal damage (Gross et al., 2005). DN is currently the most frequent cause of chronic renal failure and, consequently, of dialysis and kidney transplantation (Pugliese, 2014). In susceptible type 2 Diabetes Mellitus (T2DM) patients, DN has a clinical time-course, which presents an asymptomatic first stage ( 2 to 10 years) with an increase in both renal volume and glomerular filtration rate and also with rising urine albumin excretion (Parving et al., 2000). At early stages, physiopathological alterations involve microalbuminuria, glomerular hyperfiltration, and hyperperfusion (Ziyadeh and Wolf, 2008).

There is increasing evidence related to the fact that changes in glomerular function are not the triggers of early alterations of DN, but correspond to post-glomerular complications (Phillips and Steadman, 2002; Magri and Fava, 2009; Thrailkill et al., 2009; Singh and Farrington, 2010; Vallon, 2011). There is a marked correlation between early tubular and cortical interstitial alterations and renal function

* Address correspondence to: M. Giraud-Billoud, mgiraudbilloud@gmail.com

This paper belongs to the 60th Anniversary Collection of the Instituto de Histología y Embriología de Mendoza (IHEM) decline with worsening of prognosis (Thomas et al., 2005; Singh and Farrington, 2010). The role of protein transporters in proximal tubule cell, as a hypothetical pathophysiological mechanism of the beginning of DN, has received attention recently and it will be one of the research topics of the present study.

Autophagy is a cellular homeostatic process that allows the cell to degrade and recycle damaged cellular components such as organelles and proteins (Kundu and Thompson, 2008; Mizushima et al., 2008; Eskelinen and Saftig, 2009). An imbalance in the autophagy process has been related to the pathogenesis of $\mathrm{DN}$, describing its inhibition in animal models of type 1 and 2 diabetes mellitus (T1DM and T2DM, respectively), but its role in tubular protein transport is unknown (Yamahara et al., 2013; Ding and Choi, 2015). DN autophagic alterations in proximal tubule cells could affect the endocytic recycling pathway of surface protein transporters and may cause cellular injury and apoptosis (Christensen et al., 2012; Giraud Billoud et al., 2017).

Under physiological conditions, proteins that are filtered in the glomerulus are reabsorbed almost entirely by receptormediated endocytosis in the proximal tubule (Christensen et al., 2009; Christensen et al., 2012). In DN, a glomerular hyperfiltration initially occurs without structural damage, 
leading to proteins and especially albumin being found in the tubular lumen (Comper et al., 2008; Russo et al., 2009). Protein excess in the tubular lumen could be the initial trigger to induce cellular injury (Bryniarski et al., 2018) or the consequence of the incapability of proximal tubule to reabsorb them, as a result of the affectation of the specific transporters megalin and cubilin (Peres and Michelacci, 2015; Figueira et al., 2017; Giraud Billoud et al., 2017).

The aims of this study were to evaluate the role of autophagy at early stages of DN induced in T2DM mouse and its relationship with endocytic protein receptors.

For this purpose. male $\mathrm{C} 57 \mathrm{BKSdb}^{+/-}$(control group) and C57BKS ${ }^{\mathrm{db} / \mathrm{db}}$ (T2DM group) mice (Jackson Laboratory) were used. The animals were housed at constant temperature $\left(22 \pm 2^{\circ} \mathrm{C}\right)$ and $60 \%$ relative humidity, with a $12: 12 \mathrm{~h}$ lightdark cycle and unrestricted access to a standard rodent diet and autoclaved water. $\mathrm{C} 57 \mathrm{BKS} \mathrm{S}^{\mathrm{db} / \mathrm{db}}$ mice are leptin gene homozygous deficient mutants, what gives them susceptibility to obesity and insulin resistance (Wolf, 2013). After developing hyperglycemia, these animals show a decline in renal function (15-18 weeks-old, Cohen et al., 2000; Lim et al., 2009), showing albuminuria and reduced renal function at around 30 weeks old (Tesch and Lim, 2011). Both groups were sacrificed at 32 weeks old, and sample collections were done. Blood insulin, urinary levels of marker enzymes of proximal tubule damage (gamma-glutamyl transpeptidase -GGT-, and alkaline phosphatase -ALP-), vitamin D protein transporter (VDBP) were measured; while proximal tubule ultrastructural alterations, autophagy vesicles quantification in tubular cells and the expression of autophagy markers (lysobisphosphatidic acid -LBPA-, LC3, and p62) were determined in tissue samples. Also, megalin and cubilin expression were measured.

Thirty two-weeks-old T2DM mice showed a significant decrease in insulin levels (control: $0.98 \pm 0.01 \mu \mathrm{g} / \mathrm{L}-\mathrm{T} 2 \mathrm{DM}$ : $0.40 \pm 0.02 \mu \mathrm{g} / \mathrm{L}, t$ Student, $P<0.05)$ and a markedly high level of plasma glucose, compared to control animals (control: $150.5 \pm 11.1 \mathrm{mg} / \mathrm{dL}-\mathrm{T} 2 \mathrm{DM}$ : $652.5 \pm 9.0 \mathrm{mg} / \mathrm{dL}$, Mann Whitney, $P<0.05)$. DN was evidenced by the presence of albuminuria (control: $8.3 \pm 2.1 \mu \mathrm{g}$ albumin/mg creatinine-T2DM: $98.4 \pm 11.1$ $\mu \mathrm{g} / \mathrm{mg}, t$ Student, $P<0.05)$. Tubular injury was evaluated by the presence in urine of ALP (measured by a kinetic method, according to IFCC Tietz et al., 1983) and GGT (measured by kinetic method, a according to DGKC Szasz, 1969) because both intracellular enzymes were released to the lumen when proximal tubule cells are damaged (Raab, 1972; Hong and Chia, 1998). Also, tubulointerstitial fibrosis was measured by (a) histochemical analysis, evaluating interstitial collagen deposition by a modified point-counting technique (Møller and Skriver, 1985) applied to tissue sections stained following the Masson trichrome method; (b) immunofluorescence (IFI) analysis, quantifying a-SMA ( $\alpha$-SMA, ab5694, AbCAM) immunoreactivity levels in the kidney interstitium.

Increased levels of GGT (control: $291.3 \pm 41.3 \mathrm{U} / \mathrm{mg}$ -T2DM: $752.8 \pm 219.2 \mathrm{U} / \mathrm{mg}$ creatine, $P<0.05 t$ student) and ALP (control: 10.5 $\pm 1.4 \mathrm{U} / \mathrm{mg}-\mathrm{T} 2 \mathrm{DM}$ : $146.9 \pm 26.6 \mathrm{U} / \mathrm{mg}$ creatine, $P<0.05 t$ student) in diabetic animals indicated damage at the cellular level, as a consequence of tissue injury induced by DN. However, no tubulointerstitial fibrosis was observed, (data not shown), indicating that kidney damage was at an early stage and, therefore, at an adequate stage to evaluate the role of autophagy at the onset and evolution of DN.

Autophagy maintains normal cellular functioning, but if it is not able to achieve it, a triggering of apoptosis would follow (Rubinstein and Kimchi, 2012; Murrow and Debnath, 2013). Transmission electron microscopy (TEM; Fig. 1) was performed according to Giraud-Billoud et al. (2017) and used to quantify the number of autophagic vesicles per cytoplasmic area and the percentage of the cytoplasmic area occupied by vesicles ( 3 cells per tubule and at least 5 tubules were studied in each case) (Ylä-Anttila et al., 2009). Statistical analysis showed that there were no significant differences in the number of autophagic vesicles between groups (Fig. 1A); however, the size of these vesicles was significantly higher in diabetic than in control animals, which may be associated with a more advanced stage of the vesicles (Fig. 1B).

During autophagosome formation, some proteins can be used as markers of vesicles formation. Recent studies have shown that their expression is altered in DN, as a consequence of autophagy inhibition (Yamahara et al., 2013; Ding and Choi, 2015). Particularly, a shift of LC3 isoform I to isoform II is indicatives of autophagosome formation (Deretic, 2008; Klionsky et al., 2012).

Protein p62 is incorporated into autophagosomes through direct binding to LC3 and is degraded. Total cellular expression levels of p62 inversely correlate with autophagic activity (Mizushima et al., 2010). In DN, according to some authors (Yamahara et al., 2013; Ding and Choi, 2015), it would be expected a shift of the isoform I of LC3 to isoform II, with an increase in p62 levels, when the maturation process and formation of the autophagolysosome were inhibited (Deretic, 2008; Klionsky et al., 2012). In our study, Western Blot analysis showed that the isoform II/ isoform I ratio was significantly decreased in $\mathrm{DN}$, as compared to the control group (Anti-LC3B antibody, ab51520, ABCAM) (Fig. 1G). Furthermore, p62 protein was also significantly decreased in T2DM animals, as compared to control animals (anti-SQSTM1/p62 antibody, ab64134, ABCAM) (Fig. 1H). These results indicate that the autophagic process would have continued to some extent, but apparently, it was not able to maintain normal function, and the cells could undergo apoptosis.

Finally, proximal tubules of T2DM animals showed an increase in the number of autophagic vesicles marked by immunofluorescence (LBPA, Molecular Probes), while megalin (sc-16478, Santa Cruz) and cubilin (sc-20609, Santa Cruz) did not show any altered distribution at the brush border of proximal tubule cells (Fig. 2). However, the expression (semi-quantitation by Western Blot technique) of both albumin transporters was decreased and megalin showed significant differences to the control group (Fig. 2 ). These results were in agreement with the increased urinary levels of albumin and vitamin $\mathrm{D}$ binding protein (VDBP ELISA kit, Biomatic); control: $44.5 \pm 11.7 \mathrm{ng} / \mathrm{mg}-$ T2DM: $702.1 \pm 89.8 \mathrm{ng} \mathrm{VDBP} / \mathrm{mg}$ creatine, $t$ Student, $P<0.05)$ observed in DN animals. VDBP is a specific protein transported by megalin and cubilin and their significant increase in urinary excretion indicate tubular endocytic transporters alteration. 


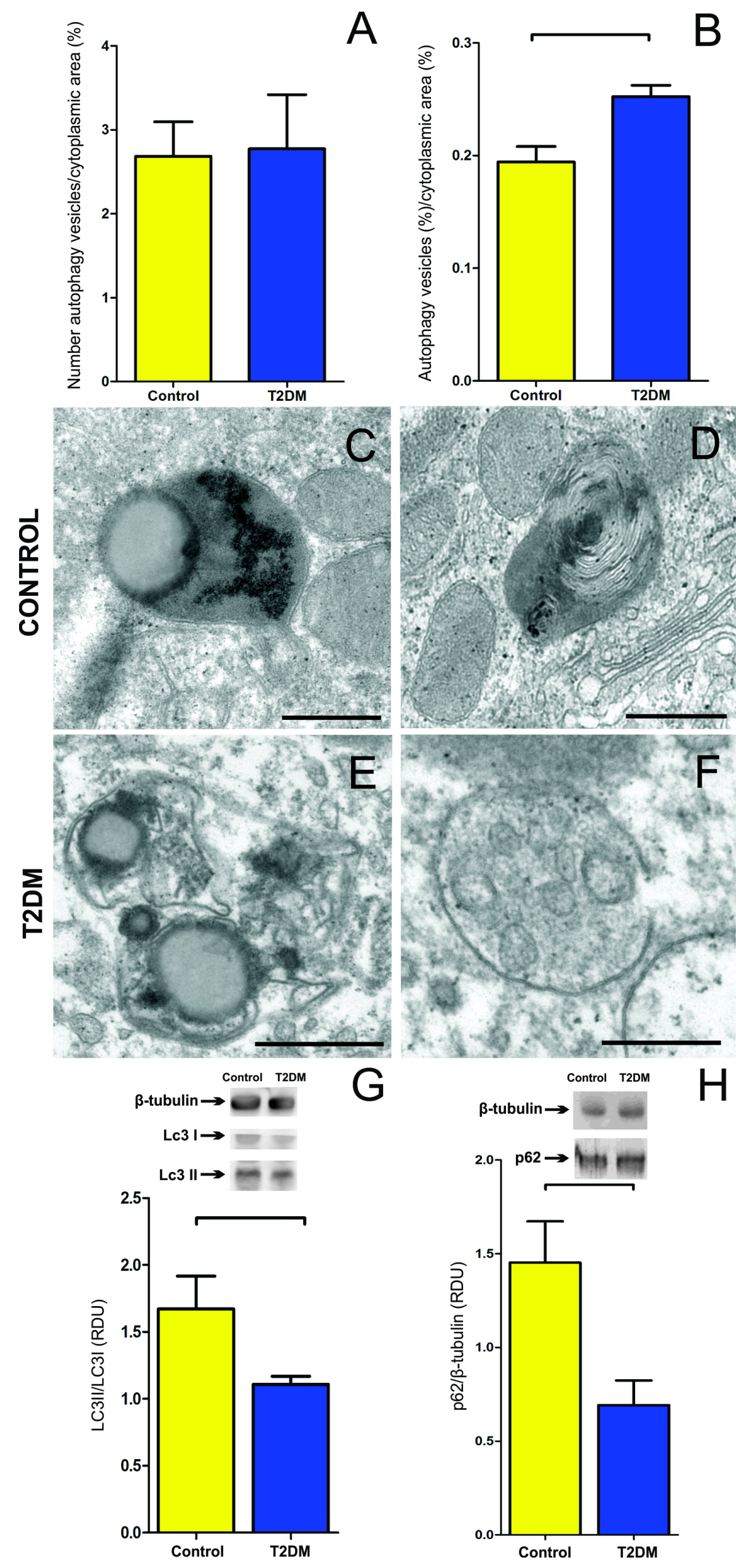

FIGURE 1. (A-F) TEM images and morphometric analysis of proximal tubule cells. Cell borders were traced using ImageJ (National Institutes of Health, Bethesda, MD, USA), as well as areas of autophagic events, obtaining each area $\left(\mu \mathrm{m}^{2}\right)$. We quantified (A) the number of autophagic vesicles as percent of the cytoplasmic area and (B) autophagic volume as a percentage of cytoplasmic volume in control (C and D) and T2DM animals (E and F). (G) Renal cortex Western Blot signal ratio between LC3-I and LC3-II, normalized to a loading control ( $\beta$-tubulin, T4026, Sigma-Aldrich), and $(\mathrm{H})$ p62 protein levels (RDU is relative density units of protein/ $\beta$-tubulin). Values are mean \pm SEM, $N=6$. Horizontal brackets indicate significant differences between T2DM and control groups (Student's $t$-test, $P<0.05)$. Scale bars: C-E: $0.5 \mu \mathrm{m}$; F: $0.25 \mu \mathrm{m}$. 

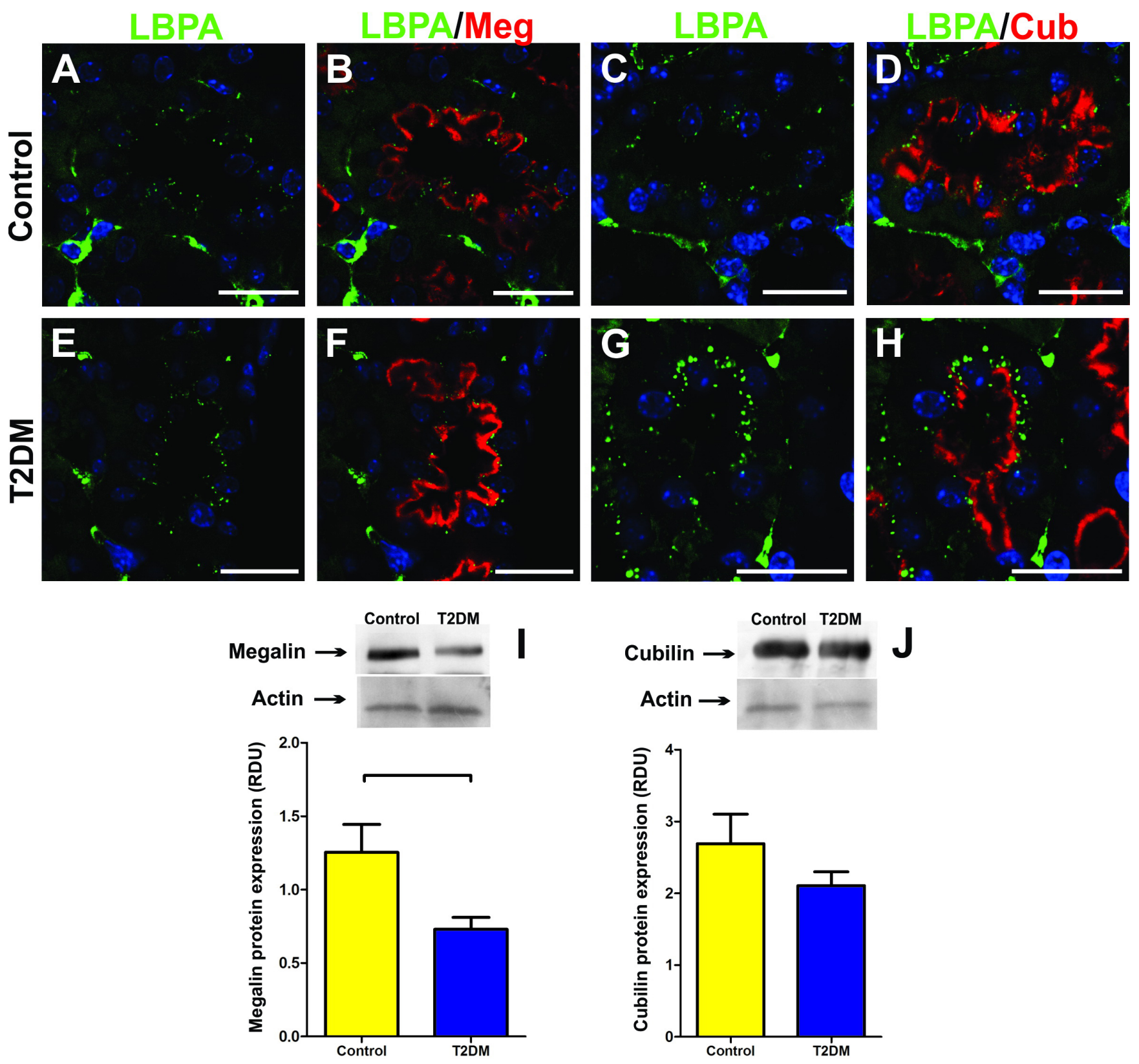

FIGURE 2. (A-H) Evaluation of subcellular trafficking of albumin transporters (megalin and cubilin) in T2DM and control animals. Images from the upper panels show the presence of LBPA protein (late endosome marker, green) and their co-localization with megalin and cubilin (red) in control (A-D) and T2DM animals (E-H) (N=4). (I-J) Renal megalin and cubilin protein levels measured by Western blot in both groups (RDU is relative density units of megalin or cubilin/actin). Values are mean \pm SEM, $N=6$. Horizontal brackets indicate significant differences between T2DM and control groups (Student's $t$-test, $P<0.05$ ). Bars: $25 \mu \mathrm{m}$.

Previous studies in T1DM animal models have shown a decrease in proximal tubule megalin levels related to hyperalbuminuria (Tojo et al., 2001; Mori et al., 2016; Figueira et al., 2017; Giraud Billoud et al., 2017). Nonetheless, in T2DM animal models, the observations have been less conclusive. Apparently, at early stages of DN, the presence of high albumin levels in proximal tubule lumen induces an increase in megalin expression (Bryniarski et al., 2018) and the endocytosis of compounds usually absent in the glomerular filtrate (e.g. high molecular weight proteins, advanced glycation end products, and other albumin-bound compounds), these substances could cause cellular injury that contributes to DN progression (Birn and Christensen, 2006).
We propose that increases in deleterious substances in the proximal tubule induce autophagic dysfunction in tubule cells, with subsequent alterations in the homeostasis of organelle recycling, leading to cell death and the activation of further mechanisms of tubular damage, such as oxidative stress, inflammation, and fibrosis, which are observed at advanced stages of DN.

Future studies will be needed to disclose the contribution of autophagy, and its relation with the protein transporters megalin and cubilin, to DN progression. 


\section{Acknowledgments}

This work was supported by grants from FONDECyT PD2014 [3140024] and Fundación Florencio Fiorini (Beca Estímulo para Investigación en Medicina 2016) to M. GiraudBilloud.

\section{References}

Birn H, Christensen E (2006). Renal albumin absorption in physiology and pathology. Kidney International 69: 440-449.

Bryniarski MA, Yee BM, Jaffri I, Chaves LD, Yu JA, Guan X, Ghavam N, Yacoub R, Morris ME (2018). Increased megalin expression in early type 2 diabetes: Role of insulin signaling pathways. American Journal of Physiology-Renal Physiology 315: F1191-F1207.

Cohen MP, Masson N, Hud E, Ziyadeh F, Han DC, Clements RS (2000). Inhibiting albumin glycation ameliorates diabetic nephropathy in the $\mathrm{Db} / \mathrm{Db}$ mouse. Nephron Experimental Nephrology 8: 135-143.

Comper WD, Hilliard LM, Nikolic-Paterson DJ, Russo LM (2008). Disease-Dependent Mechanisms of Albuminuria. American Journal of Physiology-Renal Physiology 295: F1589-F1600.

Christensen EI, Verroust PJ, Nielsen R (2009). Receptor--mediated endocyrosis in renal proximal tubule. Pflügers ArchivEuropean Journal of Physiology 458: 1039-1048.

Christensen EI, Birn H, Storm T, Weyer K, Nielsen R (2012). Endocytic receptors in the renal proximal tubule. Physiology 27: 223-236.

Deretic V (2008). Autophagosome and Phagosome. Springer.

Ding Y, Choi ME (2015). Autophagy in Diabetic Nephropathy. Journal of Endocrinology 224: R15-R30.

Eskelinen EL, Saftig P (2009). Autophagy: A Lysosomal Degradation Pathway with a Central Role in Health and Disease. Biochimica et Biophysica Acta (BBA)-Molecular Cell Research 1793: 664-673.

Figueira MF, Castiglione RC, De Lemos Barbosa CM, Ornellas FM, Da Silva Feltran G, Morales MM, Da Fonseca RN, De SouzaMenezes J (2017). Diabetic Rats Present Higher Urinary Loss of Proteins and Lower Renal Expression of Megalin, Cubilin, Clc-5, and Cftr. Physiological Reports 5.

Giraud Billoud MG, Ezquer F, Bahamonde J, Ezquer M (2017). Tubulointerstitial injury and proximal tubule albumin transport in early diabetic nephropathy induced by type 1 diabetes mellitus. Biocell 41: 1-12.

Gross JL, De Azevedo MJ, Silveiro SP, Canani LH, Caramor ML, Zelmanovitz T (2005). Diabetic nephropathy: Diagnosis, prevention, and treatment. Diabetes Care 28: 164-176.

Hong CY, Chia KS (1998). Markers of diabetic nephropathy. Journal of Diabetes and its Complications 12: 43-60.

Klionsky DJ, Abdalla FC, Abeliovich H, Abraham RT, AcevedoArozena A, Adeli K, Agholme L, Agnello M, Agostinis P, Aguirre-Ghiso JA (2012). Guidelines for the use and interpretation of assays for monitoring autophagy. Autophagy 8: $445-544$.

Kundu M, Thompson CB (2008). Autophagy: Basic principles and relevance to disease. Annual Review of Pathology: Mechanisms of Disease 3: 427-455.
Lim A, Ma F, Nikolic-Paterson D, Thomas M, Hurst L, Tesch G (2009). Antibody blockade of C-Fms suppresses the progression of inflammation and injury in early diabetic nephropathy in obese Db/Db mice. Diabetologia 52: 1669-1679.

Magri CJ, Fava S (2009). The role of tubular injury in diabetic nephropathy. European Journal of Internal Medicine 20: 551-555.

Mizushima N, Levine B, Cuervo AM, Klionsky DJ (2008). Autophagy fights disease through cellular self-digestion. Nature 451: 1069.

Mizushima N, Yoshimori T, Levine B (2010). Methods in mammalian autophagy research. Cell 140: 313-326.

Møller JC, Skriver E (1985). Quantitative ultrastructure of human proximal tubules and cortical interstitium in chronic renal disease (hydronephrosis). Virchows Archiv. A, Pathological Anatomy and Histopathology 406: 389-406.

Mori KP, Yokoi H, Kasahara M, Imamaki H, Ishii A, Kuwabara T, Koga K, Kato Y, Toda N, Ohno S (2016). Increase of total nephron albumin filtration and reabsorption in diabetic nephropathy. Journal of the American Society of Nephrology: ASN. 2015101168.

Murrow L, Debnath J (2013). Autophagy as a stress response and quality control mechanism-implications for cell injury and human disease. Annual Review of Pathology 8: 105.

Parving H, Osterby R, Ritz E (2000). Diabetic Nephropathy. WB Saunders, Philadelphia.

Peres GB, Michelacci YM (2015). The role of proximal tubular cells in the early stages of diabetic nephropathy. Journal of Diabetes \& Metabolism 6: 551 .

Phillips A, Steadman R (2002). Diabetic nephropathy: The central role of renal proximal tubular cells in tubulointerstitial injury.

Pugliese G (2014). Updating the natural history of diabetic nephropathy. Acta Diabetologica 51: 905-915.

Raab WP (1972). Diagnostic value of urinary enzyme determinations. Clinical Chemistry 18: 5-25.

Rubinstein AD, Kimchi A (2012). Life in the balance-A mechanistic view of the crosstalk between autophagy and apoptosis. Journal of Cell Science 125: 5259-5268.

Russo LM, Sandoval RM, Campos SB, Molitoris BA, Comper WD, Brown D (2009). Impaired tubular uptake explains albuminuria in early diabetic nephropathy. Journal of the American Society of Nephrology 20: 489-494.

Singh DK, Farrington K (2010). The tubulointerstitium in early diabetic nephropathy: Prime target or bystander? International Journal of Diabetes in Developing Countries 30: 185-190.

Szasz G (1969). A kinetic photometric method for serum $\Gamma$-glutamyl transpeptidase. Clinical Chemistry 15: 124-136.

Tesch GH, Lim AKH (2011). Recent insights into diabetic renal injury from the $\mathrm{Db} / \mathrm{Db}$ mouse model of type 2 diabetic nephropathy. American Journal of Physiology-Renal Physiology 300: F301-F310.

Thomas M, Burns W, Cooper M (2005). Tubular changes in early diabetic nephropathy. Advances in Chronic Kidney Disease 12: 177-186.

Thrailkill KM, Nimmo T, Bunn, RC, Cockrell GE, Moreau CS, Mackintosh S, Edmondson RD, Fowlkes JL (2009). Microalbuminuria in type 1 diabetes is associated with enhanced excretion of the endocytic multiligand receptors megalin and cubilin. Diabetes Care 32: 1266-1268. 
Tietz N, Rinker A, Shaw L (1983). IFCC methods for the measurement of catalytic concentration of enzymes Part 5. IFCC method for alkaline phosphatase (Orthophosphoricmonoester phosphohydrolase, alkaline optimum, Ec 3.1. 3.1). Journal of Clinical Chemistry and Clinical Biochemistry 21: 731-748.

Tojo A, Onozato M, Ha H, Kurihara, H, Sakai T, Goto A, Fujita T, Endou, H (2001). Reduced albumin reabsorption in the proximal tubule of early-stage diabetic rats. Histochemistry and Cell Biology 116: 269-276.

Vallon V (2011). The proximal tubule in the pathophysiology of the diabetic kidney. American Journal of Physiology. Regulatory, Integrative and Comparative Physiology 300: R1009-R1022.

Wolf G (2013). Diabetes and Kidney Disease. Wiley-Blackwell.
Yamahara K, Yasuda M, Kume S, Koya D, Maegawa H, Uzu T (2013). The role of autophagy in the pathogenesis of diabetic nephropathy. Journal of Diabetes Research 2013.

Ylä-Anttila P, Vihinen H, Jokitalo E, Eskelinen EL (2009). Monitoring autophagy by electron microscopy in mammalian cells. Methods in Enzymology 452: 143-164.

Ziyadeh FN, Wolf G (2008). Pathogenesis of the podocytopathy and proteinuria in diabetic glomerulopathy. Current Diabetes Reviews 4: 39-45. 